\title{
Acute airway obstruction due to benign multinodular goitre
}

\author{
Teresa Dias, ${ }^{1}$ Arsénio Santos, ${ }^{1}$ Carlos Mesquita, ${ }^{2}$ Rui M Santos ${ }^{1}$
}

${ }^{1}$ Internal Medicine, Centro Hospitalar e Universitario de Coimbra EPE, Coimbra, Portugal ${ }^{2}$ Surgery, Centro Hospitalar e Universitario de Coimbra EPE, Coimbra, Coimbra, Portugal

Correspondence to DrTeresa Dias, teresa.dias00@gmail.com

Accepted 9 March 2019

\section{SUMMARY}

Benign multinodular goitre is a common illness. When accompanied by obstructive symptoms, such as dyspnoea, it carries an indication for surgery. Benign multinodular goitres rarely cause acute airway obstruction. We report the case of a 88-year-old woman who presented with acute shortness of breath and stridor. A chest CT revealed marked enlargement of the thyroid gland, with an extensive intrathoracic component. She was proposed for total thyroidectomy. Her intraoperative course was unremarkable, but the patient passed away in postoperative period from ventricular fibrillation. Recognition of these cases is important, as they constitute a preventable cause of mortality if timely diagnosed and treated.

\section{BACKGROUND}

Benign multinodular goitre is a common problem but rarely cause acute airway obstruction.

The incidence of benign goitre causing acute airway obstruction is $0.6 \%$. Upper airway obstruction due to goitre is frequently under-diagnosed because the progressive and insidious growth allows the patient time to compensate and remain asymptomatic for up to $70 \%$ of tracheal compression. Large goitre with obstructive symptoms, including dyspnoea, are indicated for surgery. ${ }^{1-5}$

\section{CASE PRESENTATION}

An 88-year-old woman was admitted to the emergency room presenting with acute dyspnoea and

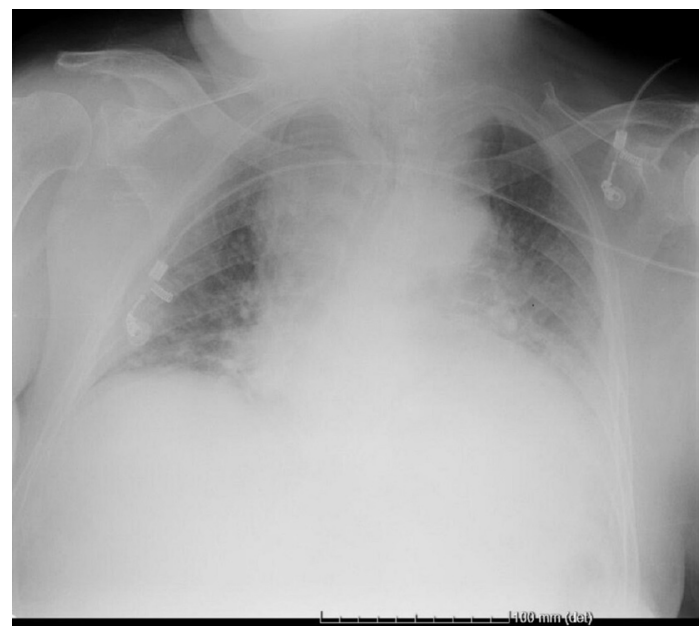

Figure 1 Chest radiography showed marked widening of the upper mediastinum.

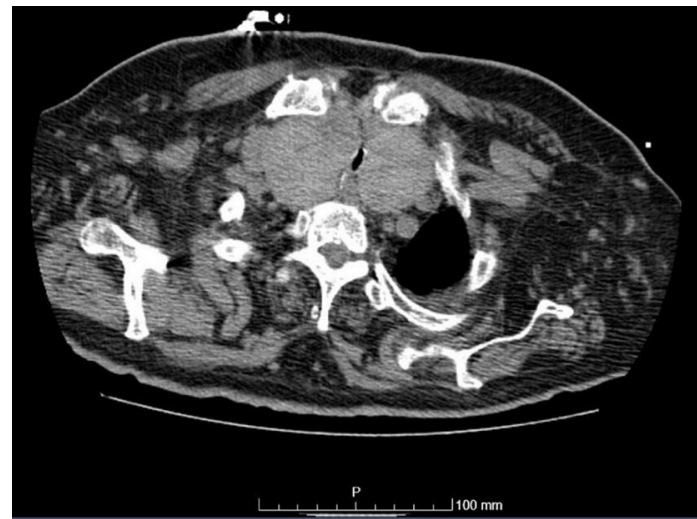

Figure 2 Chest CT revealed that trachea was compressed by the marked enlargement of the thyroid gland.

stridor. She had a history of progressive exertional dyspnoea and fatigue throughout the previous year, and had no hyperthyroid or hypothyroid symptoms.

The patient had prior known history of aortic stenosis, systemic arterial hypertension and dyslipidaemia. She had no personal or family history of thyroid malignancies or goitres.

On physical examination, she was afebrile, polypnoeic, tachycardic and had a peripheral oxygen saturation of $88 \%$ despite high-flow oxygen supplementation. She exhibited stridor and, on both lung fields, crackles and wheezing.

Arterial blood gas sampling showed hypoxaemia (pO2 $59.5 \mathrm{~mm} \mathrm{Hg}$ ) and absence of hypercapnoea. Chest radiography (figure 1) showed marked widening of the upper mediastinum. ECG showed sinus rhythm, a heart rate of $120 \mathrm{bpm}$, along with a left branch block pattern. Her laboratory tests revealed a brain natriuretic peptide of $157 \mathrm{pg} / \mathrm{mL}$, thyroid-stimulation hormone level of $0.044 \mathrm{uUI} /$ $\mathrm{mL}$ (reference range: $0.4-4.0$ ) and free T4 level of 1.1 (reference range: 0.8-1.9).

A chest CT (figure 2) was performed which revealed marked enlargement of the thyroid gland, with an extensive intrathoracic component which impinged on and compressed the superior half of the trachea, which was left with a minimum luminal calibre of $2 \mathrm{~mm}$.

Both of the brachycephalic trunks also suffered from extrinsic compression from the thyroid, with marked luminal stenosis. Also present was a left pleural effusion of reduced volume and atelectasis of both inferior pulmonary lobes. No adenopathies were observed. 


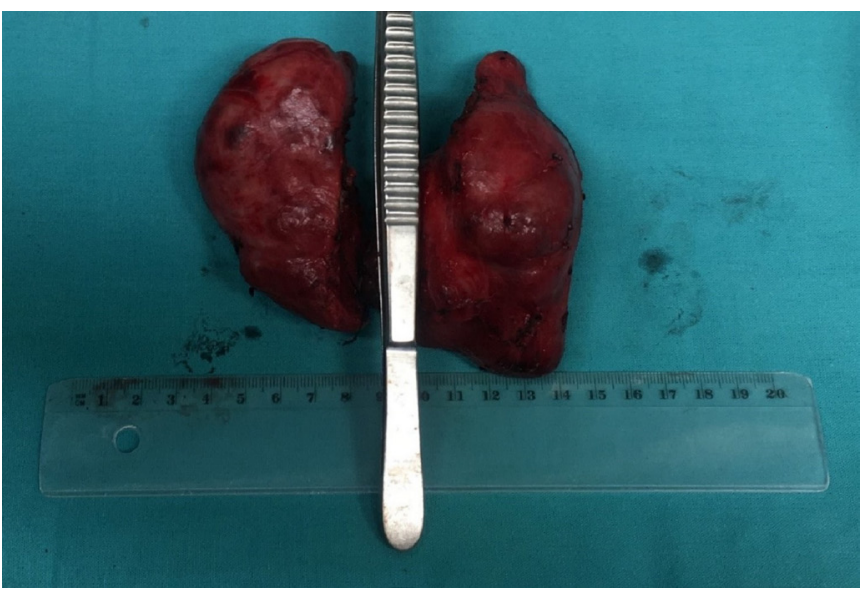

Figure 3 Total resection of the thyroid gland with $202 \mathrm{~g}$.

\section{TREATMENT}

The patient was treated with furosemide, epinephrine, bronchodilators and corticosteroids (both inhaled and intravenous), with mild improvement of her symptoms.

She was admitted to the hospital ward for stabilisation. Throughout her period of admission, she improved from her respiratory failure and stridor. Despite this, she maintained the necessity for oxygen supplementation and intravenous corticosteroids.

She was proposed for total thyroidectomy. Thyroidectomy was performed through a cervical incision and sternotomy, in collaboration with cardio-thoracic surgeons, in order to achieve safe removal of the goitre.

\section{OUTCOME AND FOLLOW-UP}

The surgery was without complications and the thyroid was fully removed (figure 3). The parathyroid glands and recurrent laryngeal nerve of both sides were identified and preserved. The trachea was normal with no features of tracheomalacia. Despite this, the patient died in postoperative day 2 from ventricular fibrillation.

The histopathology of the thyroid with a mass of $202 \mathrm{~g}$, revealed a benign multinodular goitre, with all the parenchyma

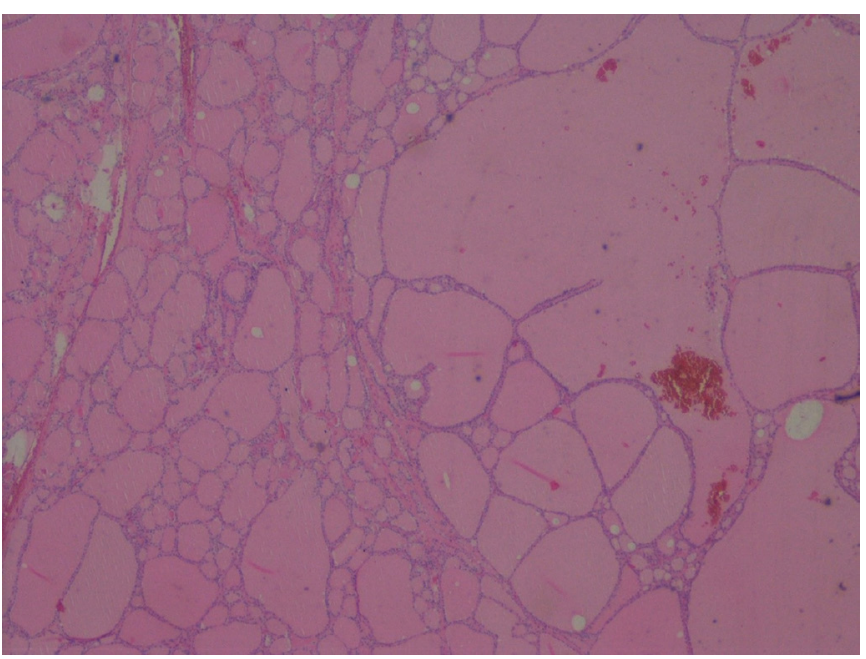

Figure $4 \quad H \& E$ (magnification $\times 40$ )—nodular hyperplasia, some nodules partially or completely capsulated, macrofollicular pattern, nodules with monotonous follicular epithelium.

\section{Learning points}

- Benign goitre causing acute airway obstruction is rare.

- Deaths from benign multinodular goitres due to airway obstruction, should be prevented.

- CT scanning has become the gold-standard for assessment of retrosternal goitre.

- Surgical intervention is the treatment of choice for substernal goitre.

occupied by nodular hyperplasia, some nodules partially or completely capsulated, macrofollicular pattern, nodules with monotonous follicular epithelium (figure 4).

\section{DISCUSSION}

Here we present the case of a patient bearing an illness that usually carries a benign presentation. In the cases of airway obstruction, such as the one described above; however, it may carry fatal outcomes.

This patient had no previous history of thyroid illness. Six years prior to her admission, she had undergone chest radiography which exhibited superior mediastinal enlargement and that was, at that time, overlooked.

Multinodular goitres can persist asymptomatic and may be discovered incidentally on a routine chest radiography. ${ }^{4}$

Deaths for airway obstruction due to benign multinodular goitre, should be avoided, since that these are benign and usually have a low mortality rate. ${ }^{6}$

Risk factors for acute airway obstruction in benign multinodular goitre appear to be oedema of tracheal mucosa, bleeding and secretion retention, which may be caused by acute airway infection. The evaluation of goitre size is a poor predictor of upper airway obstruction. CT scanning has become the gold-standard for assessment of retrosternal goitre extension and its relation to adjacent structures, and can be used to define the group of patients likely to require thoracic approach. ${ }^{7-9}$

Menon et al revealed that upper airway obstruction in patients with asymptomatic multinodular goitre was mostly unpredictable and was independent of the duration of the goitre, symptoms volume of the goitre or the presence of intrathoracic extension. They also demonstrate that the presence of upper airway obstruction on pulmonary function test in the evaluated patients did not correlate with the tracheal reduction detected in the CT scan. ${ }^{10}$

Recognition of these cases is important, as they constitute a preventable cause of mortality if timely diagnosed and treated.

Surgical intervention is the treatment of choice for substernal goitre. ${ }^{1112}$ Patients who have tracheal compression or those who become symptomatic with neck extension may pose significant hazards during induction of anaesthesia. ${ }^{13}$

The possible postoperative complications consist of hypoparathyroidism, vocal cord paralysis and bleeding and the incidence of complications after thyroidectomy for substernal or cervical goitres are similar. The histopathological diagnosis of substernal goitres are comparable with those of cervical thyroid masses, with the same incidence of malignancy. ${ }^{14-16}$

Acknowledgements We thank Dr João Bernardo and Dr. Luciano for their valuable assistance during the Surgery. We also thank Professor Armando Carvalho for critical revision of the article.

Contributors TD was responsible for data collection, literature review, writing of the manuscript and submitted the manuscript for publication. AS, CM and RMS 
provided the intellectual concept and critical revision of the article and final approval of the published version.

Funding The authors have not declared a specific grant for this research from any funding agency in the public, commercial or not-for-profit sectors.

Competing interests None declared.

Patient consent for publication Obtained.

Provenance and peer review Not commissioned; externally peer reviewed.

\section{REFERENCES}

1 Abraham D, Singh N, Lang B, et al. Benign nodular goitre presenting as acute airway obstruction. ANZ J Surg 2007;77:364-7.

2 Clark OH, Duh QY, Kebebew E, eds. Textbook of endocrine surgery. 2nd edn. Philadelphia: Saunders Elsevier, 2005.

3 Ríos A, Rodríguez JM, Canteras M, et al. Surgical management of multinodular goiter with compression symptoms. Arch Surg 2005;140:49-53.

4 Shaha AR. Surgery for benign thyroid disease causing tracheoesophageal compression. Otolaryngol Clin North Am 1990;23:391-401.

5 Sajja LR, Mannam GC, Sompalli S, et al. Multinodular goiter compressing the trachea following open heart surgery. Asian Cardiovasc Thorac Ann 2006;14:416-7.

6 Bright P, Miller MR, Franklyn JA, et al. The use of a neural network to detect upper airway obstruction caused by goiter. Am J Respir Crit Care Med 1998;157:1885-91.
7 Gittoes NJ, Miller MR, Daykin J, et al. Upper airways obstruction in 153 consecutive patients presenting with thyroid enlargement. BMJ 1996;312:484.

8 Ito T, Shingu K, Maeda C, et al. Acute airway obstruction due to benign asymptomatic nodular goiter in the cervical region: A case report. Oncol Lett 2015;10:1453-5.

9 Grainger J, Saravanappa N, D'Souza A, et al. The surgical approach to retrosternal goiters: the role of computerized tomography. Otolaryngol Head Neck Surg 2005;132:849-51.

10 Menon SK, Jagtap VS, Sarathi V, et al. Prevalence of upper airway obstruction in patients with apparently asymptomatic euthyroid multi nodular goitre. Indian J Endocrinol Metab 2011;15(Suppl 2):S127-31.

11 Raffaelli M, De Crea C, Ronti S, et al. Substernal goiters: incidence, surgical approach, and complications in a tertiary care referral center. Head Neck 2011;33:1420-5.

12 Wexler S, Yamane K, Fisher KW, et al. Single-stage operation for giant substernal goiter with severe coronary artery disease. Ann Thorac Cardiovasc Surg 2011;17:524-7.

13 Tunc M, Sazak H, Karlilar B, et al. Coexistence of Obstructive Sleep Apnea and Superior Vena Cava Syndromes Due to Substernal Goitre in a Patient With Respiratory Failure: A Case Report. Iran Red Crescent Med J 2015;5:e18342.

14 Arici C, Dertsiz L, Altunbas H, et al. Operative management of substernal goiter: analysis of 52 patients. Int Surg 2001;86:220-4.

15 Ozdemir A, Hasbahceci M, Hamaloglu E, et al. Surgical treatment of substernal goiter. Int Surg 2000;85:194-7.

16 Wright CD, Mathisen DJ. Mediastinal tumors: diagnosis and treatment. World J Surg 2001;25:204-9.

Copyright 2019 BMJ Publishing Group. All rights reserved. For permission to reuse any of this content visit

https://www.bmj.com/company/products-services/rights-and-licensing/permissions/

BMJ Case Report Fellows may re-use this article for personal use and teaching without any further permission.

Become a Fellow of BMJ Case Reports today and you can:

- Submit as many cases as you like

- Enjoy fast sympathetic peer review and rapid publication of accepted articles

- Access all the published articles

Re-use any of the published material for personal use and teaching without further permission

For information on Institutional Fellowships contact consortiasales@bmjgroup.com

Visit casereports.bmj.com for more articles like this and to become a Fellow 